\title{
Crisis in Boeing 787 Dreamliner: An Investigation from Project Management Control Perspective
}

\author{
Suchandra Paul \\ University of Dundee, Dundee, Scotland, UK
}

Received: Oct. 21, 2018 Accepted: Nov. 23, 2018 Online published: Nov. 27, 2018

doi:10.5296/ijhrs.v8i4.13805 URL: https://doi.org/10.5296/ijhrs.v8i4.13805

\begin{abstract}
The organizational project management control has been the area of great interest from long time among the investigators who validated that there is a great necessity of control approaches in an organization to acquire their goals. In this paper, a detailed analysis describing the stages associated with control in project management process has been illustrated. In the first phase the proposed plans are outlined with a follow up on the deviation of the plans with causes. In the final phase a detailed solution analysis was carried on what the company did to fix the series of delays along with some suggestions stating proper ways of dealing the situations. This research gives a wide overview on the problems that 787 Dreamliner faced during its manufacturing and delivery process. The analysis was done on the control perspective. Innovative solutions was laid down which if applied during the service procedures could have avoided the problems related to delay of 787 Dreamliner's delivery. The main intention of this research is that the solutions and strategies provided can be implemented successfully to the other organization for better planning and handling of entire process ultimately minimizing the downtime and increasing the productivity of the organization.
\end{abstract}

Keywords: project management, Dreamliner 787

\section{Introduction}

Project management is the technique of systematizing the elements associated with organizational project on the basis of the criteria that the project is related to the development of a new product and also the initiation of a new utility or marketing based campaign (Mpug, 2018). The project management procedure involves methodologies to develop specific product or service. Project managers are the integral part of project management and are vested with the various roles. These roles are objectives formulation, scheduling deadlines, initiating plans for action, assignment of responsibilities and validating result thus minimizing risks, abiding with the specification and working within the budget limits 
(Pymetrics, 2018). The important aspects of a project is to carry out specific jobs which may be temporary or time limited and is also initiated by a various organization. This is termed to be as the base organization and it results in specific outcomes.

From the view point of several perspective, the main components of a project are categorized as: a) Task, b) Organizational, c) Change, d) Resource, e) Stakeholder, and f) System.

The organizational perspective reveals that project management is associated with the relationship between the permanent and temporary organization.

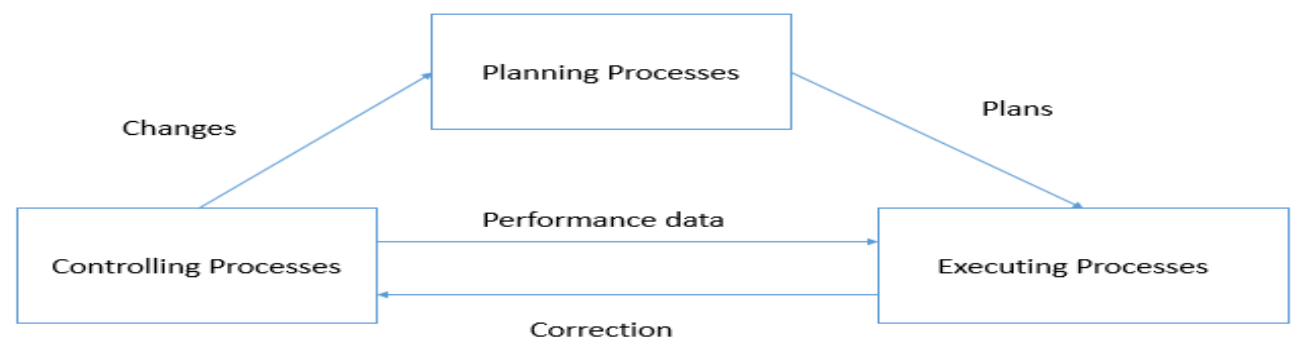

Figure 1. Project management and involved managerial processes (Mindtools, 2018)

The stages of the project establishment phase are very important as in this phase the project owner and project manager should carry out discussions session thus validating missions and goals (Mindtools, 2018):

- Mission: Suggests a situation that might occur in the base organization

- Goals: The main features of goals section is to analyze project deliverables which has to be shifted to the base organization as per schedule as well as to define quality standards, and within a set cost frame.

Various project management methodologies vested with the role to embed project successfully has been utilized vastly in the zones of planning and control of time, cost and quality. Despite of this, when the project and project management is compared, distinction is less than accurate (Munns \& Bjeirmi, 1996). From the theoretical point of view, project management can be illustrated as per with term planning, controlling and evaluation theories. The technique of providing direction and control to a project from the start till the end are subdivided in five categories as follows (Projectinsight, 2018): a) project formulation and initiation, b) defining of project with planning formulation, c) starting of project or execution, d) project control and e) closing of project.

The organizational control has been the area of great interest among the investigators who stated that there is a great necessity of control methodology in an organization to acquire the required goals (Kirsch, 1996). The terminology control is illustrated as a behavioural approach which motivates the employee of a company associated with the company project to initiate their action as per the pre validated strategy in order to acquire suitable objectives (Merchant, 1988). In relevance to the success of the project, from the view point of earlier approaches, projects have been viewed as technical systems and not considered to be a 
behavioural systems. There are positive attributes of utilizing mechanistic approach based on outcomes with the purpose of achieving target dates, acquiring financial plans as well as controlling the quality of the finished product (McCollum \& Sherman, 1991). The main process of controlling is subdivided into two categories as a) reporting and b) total change control. On the basis of the former, corrections are initiated for the executing approaches, and on the basis of the latter, changes are initiated for the planning processes (Koskela \& Howell, 2001). Project control can be categorized mainly into the following areas to be mention as project organization and follow-up plans (Packendorff, 1995). The main features of the control stage associated with the project management are

i) Stating of the current status of the project.

ii) Estimation of the degree of deviation of the current status from the proposed plans.

iii) Carrying out an investigation to unearth the cause of deviation.

iv) Problem handling with effective solutions.

v) Decisions making.

In this paper, various issue related to the control stage of project management are reviewed by taking into consideration the viewpoints on 787 Dreamliner. Initially, an overview on 787 Dreamliner is illustrated. In the next section, the illustration of formulated plans and its deviation from the proposed plan is laid down. Also, the main reasons for the deviation from the proposed plan which caused the major delay are suggested. Then the various problems are analyzed that caused the delay and suitable solutions are suggested. Finally the conclusion is presented illustrating a brief about the paper.

\section{Overview on 787 Dreamliner (Status)}

Boeing, the world's largest American aerospace company is the leader in the manufacturing world of jet transport. The initial plans and promises compelled the project Dreamliner to be considered as the most advanced and sophisticated airline to be operated (Marsh, 2009). In 16th November, 2008, around 895 Dreamliner's orders are vested to the Boeing Company from around the world of high reputation airline organization. Boeing proposed to redesign its wide-bodied jet, the A350, to make it wider. This decision is carried out due to the overwhelming response from various airline organizations towards Boeing's 787. The issues related to numerous delays associated with development stage, pushed the organization towards cost overrun thus creating an unfavorable situation for the organization.

\section{Formulated Plans and Its Deviation from the Proposed Plans}

\subsection{Initial Plans for 787 Dreamliner}

In 2003, Boeing laid down an innovative plan for developing trust and values among its traveler by formulating an advanced aircraft named the 787 Dreamliner. In the first phase, Boeing planned to improve the travel experience of its passengers through aircraft redesign and by incrementing the comfort zone of the customers thus giving significant challenges to other rival aircraft. The primary structure of the 787 Dreamliner which sums around over 50 
percent was planned to be constructed using composite materials that is carbon fibre technology (Hawk, 2005). The main advantages of composite material is that it has the capability to withstand increased humidity and pressure in the passenger cabin thus facilitating superior improvement to the flying experience.

In order to enhance the effectivity of the 787 Dreamliner performances, the use of lithium ion battery was proposed. Improved power quality and the ability to recharge quickly are the main advantages of the battery (Boeing, 2018). Boeing also proposed a plan to improvise the efficiency of the aircraft by utilizing midsize airplanes in order to supply big-jet-type flying ranges which is capable of flying at almost similar speed. This plan was formulated to add value to its customers. The suggested plans were supposed to allow airlines to offer economical non-stop flights to and from more and smaller cities. Boeing proposed an innovative plan of setting up an unconventional supply chain in the aircraft manufacturing industry in order to develop and produce the Dreamliner. The proposed plan was supposed to minimize development time for the 787 from the typical six to four years and the development cost from $\$ 10$ billion to $\$ 6$ billion. The date November 16, 2008 reveals the information that the Boeing received orders from 7 airlines that accounted for 895 Dreamliners (Commercial, 2018).

\subsection{Deviation from Proposed Plan and Ultimately Delay of Delivery of 787}

The deviation from the prospective plans is due to the following

a) Problems due to unconventional supply chain.

b) Constrains incorporated in lithium-ion battery

c) Shortage of fasteners.

d) Technical issues related to Carbon fibre

e) Numerable strikes.

\section{The Causes of Deviation from Prospective Plans thus Generating Delays (An Investigation)}

There are few important issues mentioned below, that cause a steep deviation from the proposed plans which resulted in the delay of Dreamliner supply:

\subsection{Unconventional Supply Chain}

The business strategy formulated initially was not up to the standard and also there was a lack of communication with the suppliers. These were the main reasons for delayed delivery of airlines (Tang \& Zimmerman, 2009). From the development point of view in the field of manufacturing sector, Boeing established connections with several worldwide companies from the countries like Italy, Spain and Japan. There was a lack of responsible and positive attitude from the first tier supplier as they failed to develop the required components themselves or did not make arrangements to extract the parts listed as primary requirements from the second tier suppliers thus causing delay to the entire process, hence minimizing the 
quality and ultimately paid for time (Sodhi \& Tang, 2012).

\subsection{Lithium Ion Battery}

GS Yuasa, the manufacturer of the lithium-ion battery was responsible for the 787 Dreamliner airline batteries. But the battery supplied by them found to be full of defects as it was generating severe amount of heat under the situation of thermal runaway. The first sign of faultiness was observed in 10th November, 2013 when the flight operated by Japan Airlines developed a serious problem with the battery component. This compelled the management to ground the Dreamliner flights operated by Japan airlines. It resulted in significant cost overrun and delay in flight services (Williard et. al, 2013). The investigation concluded that there was several cell failures within the battery which occurred due to mechanical deformation as well as bursting of the vent discs. This situation compelled the investigators to conclude that the battery undergone a thermal runaway where the failure of one battery cell cascaded to another neighboring cells within the battery assembly (Kolly et al., 2013).

\subsection{Scarcity of Fasteners}

The unexpected shortage of fasteners in October 2007 compelled Boeing to disclose its first delay. The norms and process to get the orders of fasteners became a tough approach and thus resulted in further delays. The unprofessional work ethics prevailing among the suppliers is the reason behind these delays as they did not document their work properly as per the standard of the federal authorities (Elahi, Sheikhzadeh, \& Lamba, 2012). The main problem of the delay is due to the reason that the aircrafts major systems was not installed in the proposed time and several parts were only attached by means of temporary fasteners (Trimble, 2007). It was the first of many delays ahead of the first test flight that made the plan delayed by nearly a year and a half (Cohan, 2009). Apart from that, some fasteners were improperly installed leading to further delays (Gates, 2008).

\subsection{Carbon Fiber Technology}

Initially, the engineers from the Boeing were not sure for the approval of carbon fiber technology for the aircraft as it was a challenging task for the Boeing engineers. The material selection was an important aspects on the part of the engineers because if the components of the plane were much heavy then the plane would not be an energy efficient one (Slayton \& Spinardi, 2016). Irrespective of that, the light components would have resulted in the failure of the aircraft structure. The second case was the primal reason for delay as it was uncovered that the structure of the center wing box was light and should necessarily be stronger for the robust structure of the aircraft component.

\subsection{Unusual Strikes}

On 6th September, 2008 there was unrest among the members of 'The Boeing members of the International association of the Machinists' as they protested by giving up their daily basis work thus adding up to the sequence of delays further delaying the delivery process. Another reason for delay is due to the strike organized the engineers union SPEEA on 10th September, 2008 (Kotha, Nolan \& Condit, 2008). 


\section{Problem Addressing and Solutions}

\subsection{Approaches by Boeing for Negotiating Problems}

The series of delays incorporated in the Dreamliner process was handled effectively by Boeing. Boeing managed to take a hold over the supplier around the world. In addition to that, in year 2008 Boeing constructed a high-tech operations center in a factory for having a track on the suppliers in real time. It was laid down for verifying that the Dreamliner components and modules are tested and implemented in a correct way before shifting it to the next stage. This step from the Boeing part was significant because the mistakes were mitigated related to the supplier mismanagement. Apart from that, the delayed program was initiated by purchasing Boeings one of its tier-1 strategic partners that is a unit of Vought Aircraft Industries, which was researched to be the weakest link of Boeing's 787 supply chain (Ray, 2008). In order to protect its composite fuselage, Boeing redesigned the fuselage by making the wing structure strong using special materials. Boeing personals performed travel related work in order to resolve issues with underperforming associates. The top management are reorganized by replacing the program manager with supply chain expert. Concessions are paid to the labor unions and outsourcing was decreased.

In accordance with the new supply chain modifications, Boeing laid down a new risk sharing contact according to which the strategic suppliers would receive payments only if the main delivery of first 787 Dreamliner to the airlines is accomplished. This novel approach involve the suppliers in 787 initiative for development. It was also profitable for the suppliers as they got access to own their intellectual property and even being licensed to other organizations in the future (Ganji et al. 2017). It came to the notice of the Boeing managers that for the system to perform efficiently, greater oversight of the supply chain system was important (Kotha \& Srikanth, 2013).

\subsection{Appropriate Approaches for Problems}

The primary delay in the organization could have been avoided or have been handled in an efficient manner if Boeing implemented innovative policies of fair sharing partnership. The outcome of this partnership would result in distribution of equal responsibilities between Boeing and the suppliers. This scheme would help in the enhancement of the working commitment and hence it will help to minimize the delay in the process. It is superiorly important that the suppliers should provide report on technical support associated with certification requirements. It is the dual responsibility of the administration as well as the actual manufacturer to carry out more audits on the suppliers' developments. The manufacturing department should develop a database holding the information on supplier's problem. There should be an approach to share the database with the administration so that they could analyze the reason of the problem and also provide innovative solution, various result analysis and the steps that the supplier took in negotiating the problems. The main reason of developing the database is to prove that supply chain connections are well defined through various arrangements.

Efficient integration of supply chain scheme is essential for networking proficiency and holds 
the integration of information flows, physical flows as well as financial flows associated with an organization and its supply chain partners (Rai, Patnayakuni, \& Seth, 2006). Apart from that, the quality should have been given priority without compromising the scheduled delivery and by this; quality product would have been expected. Lack of teamwork between the various employees should have been avoided. Successful project teamwork starts with recruiting suitable people and transforming them into a working team. Team work and team building are aimed at the activities which are implemented so that the group becomes more cohesive thus improving the moral and the efficiency of the organization. Superior team building ability helps to develop a superior organization thus generating effective performance and incrementing the productivity of the organization (Constantine, 1993). Also it is essential to generate superior risk sharing opportunities as well as incentives for strategic partners. It is important to consider customers as partners and to establish better communications with them.

The main problem associated with the Lithium Ion batteries is their flammable electrolyte solutions. In comparison to other common types of batteries which consists of electrolytes made of solutions of acid or base, the electrolyte associated to Lithium Ion cells typically consists of lithium salts in flammable organic solvents which are ethylene carbonate as well as ethyl methyl carbonate. This constraint can be handled by the means of electrolyte solutions containing phosphates as well as phosphazenes that can minimize flammability (Jacoby, 2013). These type of effective mixtures terminate radical based combustion reactions thus preventing fires. So the issue battery in Dreamliner 787 can be handled effectively by using the mentioned approach.

Since an improper documentation of work resulted in scarcity of fastener, the importance of work documentation should be given higher priority. The main attributes of proper documentation involves quality, reachability as well as history for both the solo document and for the whole project documentation. It is very much crucial that the documentation is well organized with higher readability and also should have rich content. Highly trained project managers are well capable of developing and following standard templates for their project documents. They have the skills of reutilizing the successful project procedure, business strategies, requirement sheets as well as the status of the project in order to facilitate the organization team to focus on their core competency of managing the project instead of balancing the complicated paperwork (Eshna, 2018). So a well balanced project documentation of planned work could have prevented the scarcity of fastener issues.

A setup of research and development center in the engineering department of Boeing should have been given due importance. If significant amount of research was conducted on carbon fibre technology beforehand, the delay could have been minimized.

The unusual strikes which led to significant delay in the delivery of Dreamliner 787 could have been avoided by initiating a team of human resource for creating a harmony between the management and workers. A regular session of joint interaction between the worker and management team could have minimize the unrest among the workers thus mitigating the problem of unusual strikes. 


\section{Conclusion}

Since the beginning, 787 Dreamliner was piled up with the several complicated problems. The problem related to delays and production prevented the selling of aircraft and thus making it impossible to initiate the delivery process to its customer. Lithium-ion battery problems forced the FAA to ground all 787 aircraft thereby halting the delivery of new aircraft to the customers. The most recent case of defects in 787 Dreamliner was registered on July 12, 2013; an Ethiopian airline caught fire as it was parked at a gate of Heathrow Airport (Schwartz \& Busby, 2014). An extensive research of the situation encountered during Dreamliner project can be valuable perception for major organizations around the globe to secure future successes in complicated projects accomplished jointly with suppliers. Although with several issues, the 787 Dreamliner hoping to generate significant value for Boeing over the next 20 years. If Boeing can deliver require amount of 787 aircraft as per the order, the profit generated will be around $\$ 20$ to $\$ 50$ billion in value after investment costs. In this paper, a detailed analysis describing the stages associated with control in project management process has been illustrated. In the first phase the proposed plans are outlined with a follow up on the deviation of the plans with causes. In the final phase a detailed solution analysis was carried on what the company did to fix the series of delays along with some suggestions stating proper ways of dealing the situations. This research gives a wide overview on the problems that 787 Dreamliner faced during its manufacturing and delivery process. The analysis was done on the control perspective. Innovative solutions was laid down which if applied during the service procedures could have avoided the problems related to delay of 787 Dreamliner's delivery. The main intention of this research is to provide solutions and strategies that can be implemented successfully to the other organization for better planning and handling of entire process ultimately minimizing the downtime and increasing the productivity of the organization.

\section{References}

Boeing. (2018) Batteries and Advanced Airplanes. Retrieved from http://787updates.newairplane.com/787-Electrical-Systems/Batteries-and-Advanced-Airplane s.

Cohan, P. (2009). Boeing's 787 Dreamliner faces another nightmare engineering delay. Daily Finance. Retrieved from http://www.dailyfinance.com

Commericial. (2018) Current product and services. Retrieved from http://www.boeing.com

Constantine, L. L. (1993). Work Organization-Paradigms for project management and organization. Communications of the ACM, 36(10), 35-43. https://doi.org/10.1145/163430.163435

Ehsan, E. E., Sheikhzadeh, M., \& Lamba, N. (2012) An integrated outsourcing framework: analyzing Boeing 's outsourcing program for Dreamliner (B787). Management Science and Information Systems.

Eshna. (2018) Project Documentation and its Importance. Simplilearn. Retrieved from 
https://www.simplilearn.com/project-documentation-article

Ganji, E. N., Shah, S., \& Coutroubis, A. (2017) Bridging New Product Development with Sustainable Supply Chain Management Practices. International Journal of Economics and Management Systems, 2, 178-186.

Gates, D. (2008). Boeing 787 fastener problems caused by Boeing engineers. The Seattle Times

Hawk, J. L. (2005). 787 program the Boeing Company.

Jacoby, M. (2013) Assessing The Safety Of Lithium-Ion Batteries. Chemical and Engineering News, 91(6), 33-37. https://doi.org/10.1021/cen-09106-scitech1

Kirsch, L. J. (1996) The Management of Complex Tasks in Organizations: Controlling the Systems Development Process, Organization Science, 7(1), 1-21. https://doi.org/10.1287/orsc.7.1.1

Kolly, B. J., Panagiotou, M. J., \& Czech, B. A. (2013). The Investigation of a Lithium-Ion Battery Fire Onboard a Boeing 787 by the US National Transportation Safety Board; Safety Research Corporation of America: Dothan, AL, USA, pp. 1-18.

Koskela, L. J., \& Howell, G. (2001) Reforming project management: The role of planning, execution and controlling, In 9th International Group for Lean Construction Conference, National University of Singapore.

Kotha, S., \& Srikanth, K. (2013) Managing A Global Partnership Model. Global Strategy Journal, 3, 41-66. https://doi.org/10.1111/j.2042-5805.2012.01050.x

Kotha, S., Nolan, R., \& Condit, P. M. (2008). Boeing 787: The Dreamliner (B), Foster School of Business.

Marsh, G. (2009). Boeing's 787: trials, tribulations, and restoring the dream. Reinforced Plastics, Elsevier. https://doi.org/10.1016/S0034-3617(09)70311-X

McCollum, J. K., \& Sherman, D. J. (1991). The effect of matrix organization size and number of project assignments on performance. IEEE Transactions on Engineering Management 38(1), 75-78. https://doi.org/10.1109/17.65762

Merchant, K. A. (1988) Progressing toward a Theory of Marketing Control: A Comment. Journal of Marketing, 52(3), 40-44. https://doi.org/10.1177/002224298805200304

Mindtools. (2018). Project Management Phases and Processes. Structuring your Project. Retrieved from https://www.mindtools.com/pages/article/newPPM_63.htm

Mpug. (2018). What is Project Management? Retrieved from http://www.mpug.com/education/what-is-project-management/

Munns, A. K., \& Bjeirmi, B. F. (1996). The role of project management in achieving project success. International Journal of Project Management, 14(2), 81-87. https://doi.org/10.1016/0263-7863(95)00057-7 
Packendorff, J. (1995). Inquiring into the temporary organization: new directions for project management research. ScamL J. Mgmt, 11(4), 319-333. https://doi.org/10.1016/0956-5221(95)00018-Q

Projectinsight. (2018). 5 Basic phases of project management. Retrieved from http://www.projectinsight.net/

Pymetrics. (2018). Project management. Retrieved from https://www.pymetrics.com/explore-careers/project-management/

Rai, A., Patnayakuni, R., \& Seth, N. (2006) Firm performance impacts of digitally enable supply chain integration capabilities. MIS Quarterly, 30(2), 225-246. https://doi.org/10.2307/25148729

Ray, S. (2008) Boeing buys Vought Venture to stem delays on 787. Bloomberg Press.

Schwartz, L. A., \& Busby, J. (2014). The 787 Dreamliner: Will it be a dream or nightmare for Boeing Co.?. Journal of Case Research in Business and Economics, 5.

Slayton, R., \& Spinardi, G. (2016). Radical innovation in scaling up: Boeing's Dreamliner and the challenge of socio-technical transitions. Technovation, 47, 47-58. https://doi.org/10.1016/j.technovation.2015.08.004

Sodhi, M. S., \& Tang, C. S. (2012). Managing supply chain risk, application: mitigating new product development risks - the case of the Boeing 787 Dreamliner, International Series in Operations Research \& Management Science, pp. 161-179.

Tang, C. S., \& Zimmerman, J. D. (2009). Managing new product development and supply chain risks: The Boeing 787 Case. Supply Chain Forum an International Journal, 10(2). https://doi.org/10.1080/16258312.2009.11517219

Trimble, S. (2007). Boeing 787 first flight suffers two-month delay . Flight International. Retrieved from http://www.flightglobal.com/

Williard, N., He, W., Hendricks, C., \& Pecht, M. (2013) Lessons learned from the 787 Dreamliner issue on lithium-Ion Battery reliability. Energies, 6(9), 4682-4695. https://doi.org/10.3390/en6094682

\section{Copyright Disclaimer}

Copyright for this article is retained by the author(s), with first publication rights granted to the journal.

This is an open-access article distributed under the terms and conditions of the Creative Commons Attribution license (http://creativecommons.org/licenses/by/4.0/). 